\title{
Design of a sprayer for complex treatment of tilled crops
}

\author{
Anna I. Belousova ${ }^{1, *}$, Arkadiy V. Moiseev ${ }^{1}$, and Dmitry A. Fillipov ${ }^{1}$ \\ ${ }^{1}$ FSBEI HE Kuban State Agrarian University named after I.T.Trubilin, Krasnodar, Russian Federation
}

\begin{abstract}
The article is devoted to the complex processing of tilled crops by the proposed sprayer. The article has a research character which is expressed in the fact that there was shown the analysis of methods and means of chemical protection of plants as well as the analysis of the leading scientists on the subject, promising designs that provide optimal chemical treatment of tilled crops, their shortcomings and solutions to these problems were cited. There was defined the main tendency of development of machines for chemical protection of plants, improvement of their design according to modern requirements of agricultural development. Also, there was justified the design of the sprayer, namely, the results of scientific researches, there were shown the causal relationship of the number of spraying tips from the width and the grip of working area. There was described the principle and operation process of the developed sprayer. As a result of the work there was obtained the design for the complex processing of tilled crops. The conclusions present the main results achieved so far.
\end{abstract}

Inter-row cultivation of tilled crops is one of the most important operations in the process of cultivation of cultivated plants planted in large numbers in Krasnodar Territory and other areas. The productivity of agricultural crops directly depends on inter-row cultivation and requires high qualification and responsibility of a mechanic. The concept of machinetechnological support of crop production for the period up to 2020 provides for the creation of a new generation of elements and machines for soil treatment, plant protection, grain and forage harvesters created on the basis of a systematic approach, adaptability of technological impacts depending on the zonal soil-climatic and agro-landscape conditions. The solution of this problem is based on scientific research of the process of interaction of tillage working elements with soil [1].

Development and introduction in agricultural production of high-performance sets of machines for gardening mechanization allow to reduce the labor costs for fruit production, increase significantly labor productivity and create prerequisites for the organization of high-quality industrial production in this industry. The timely protection of plants from pests and diseases is occupied an important place among the activities aimed at obtaining high and sustainable yields of fruits, berries and vegetables [2].

\footnotetext{
* Corresponding author: sergey belousov87@mail.ru
} 
According to international organizations, the annual global harvest losses of all agricultural crops account for $35 \%$ of the gross harvest of potential crops, pests account for $13.9 \%$, diseases $-9.2 \%$ and weeds $-11.4 \%$. The main task of plant protection from pests and diseases is a complete elimination or reduction of crop losses to economically imperceptible sizes through the use of integrated plant protection systems that are safe for humans and environment [3]. Production of commodities on strips is based on technologies using small-sized machinery and small-scale mechanization. The small-sized equipment includes tractors of traction class 0.6 with a set of different agricultural machines designed to perform mechanized work on soil treatment, fertilizer application, sowing, crop care, chemical plant protection, etc. They differ in overall dimensions from their elder copies, parameters of working elements and technical and economic activities [4].

Means of small mechanization (MSM) are devices driven by an engine (electric, pneumatic or internal combustion), muscular power of farm animals or humans. The use of small-scale mechanization provides increased productivity in $3 \ldots 15$ times. It is most effective to use them on small plots of land (private farms, plots of lands and other plots) and plots inaccessible to tractors, in mountainous and wetlands, when working in breeding and seed production [5]. The MSM have an increasing in the cultivation of gardens and vineyards, it can be traced on the example of technology of cultivation of perennial plants in the province of Bordeaux in France, and in our region on the example of agricultural "SAD GIGANT" of the Slavyansky district of Krasnodar Territory. Currently, the industry produces more than 400 items and MSM models, the range of which covers machines from manual mechanized tools to agricultural machines on the base of mini-tractors and motor cultivators. It is important to consider knapsack sprayers and motor cultivators and ways of combining these machines for processing small hard-to-reach areas of crops and more economical distribution of plant protection products [6].

The schematic diagram of a knapsack sprayer with manual drive is shown in Figure 1. Sprayers of this type are designed to process means of plant protection on small plots by liquids, in greenhouses and inaccessible places for to the tractor sprayers. It consists of a tank 1 (Figure 1) with a capacity of up to 20 liters, a pallet 13, a pump 9 with a manual drive 8 , a hose nozzle 6 , shoulder slings [7].

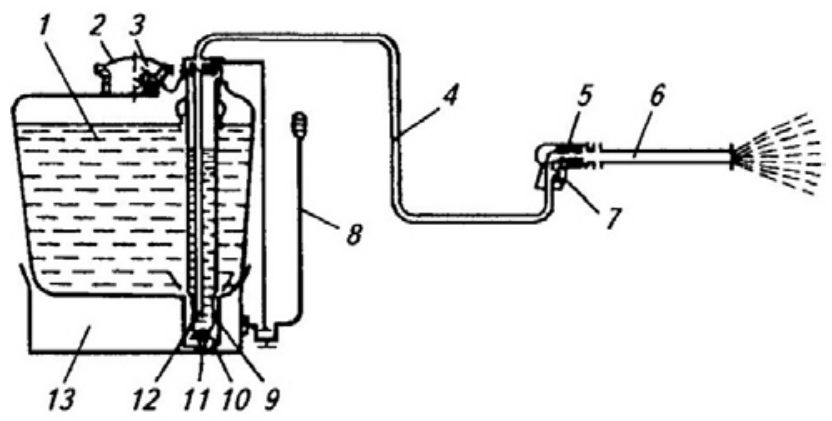

1 - tank; 2 - mouth; 3, 5 - filters; 4 - hose; 6 - hose nozzle; 7 - locking device; 8 - lever; 9 - pump; 10 - cuff; 11 - ball bearing valve; 12 - bucket; 13 - pallet

Fig. 1. Schematic diagram of a knapsack sprayer's operation with handed drive .

The sprayer is filled with a working solution through the filler mouth. The operator drives the piston with the lever for spraying. When it is moved up, the lower cavity of the pump is filled with the working liquid coming from the tank through the cuff. When the piston moves down, the working fluid is forced out of the cylinder into the upper cavity of the 
pump and compresses the air. Under the pressure of compressed air, the working liquid enters the hose nozzle and through the sprayer to the processed object. The flow of liquid is stopped under rotation of a locking device [8].

Also sprayers of this type can be equipped with electric power installations (Figure 2), with a pump that is installed at the bottom of the sprayer. The use of these types of sprayers is more important, namely, because of increased productivity and reduced load on the operator. It is possible to expand the functionality of the sprayer without introducing into the modernization of its design. The process of operation is similar to that of a manually operated sprayer, except that the pressure in the tank is created by an electric pump.

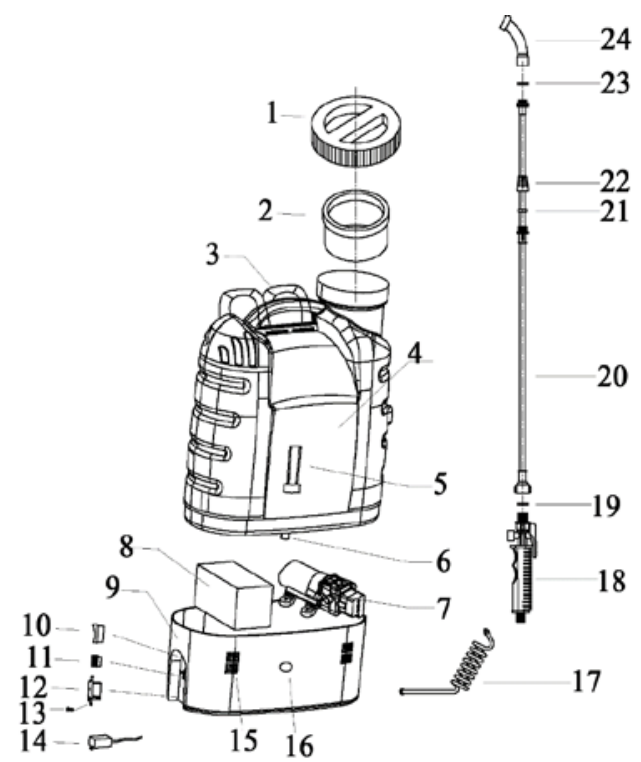

1 - tank's cover; 2 - upper tight filter; 3 - gear; 4 - tank; 5 - internal lower filter; 7 - diaphragm pump; 8 - accumulator; 9 - base; 10 - switch; 11 - regulator of power; 12 - connector for charging device; 13 - screw; 14 - charging device; 15 - regulator of spraying intensity; 16 - light indicator; 17 - hose; 18 - grip; 19, 23 - compacted ring;20 - rod; 21 - padding; 22 - connecting screw; 24 pulverized nozzle.

Fig. 2. Basic scheme of operation of a knapsack sprayer with electric drive.

Cultivators are universal energy funds on the basis of monaxonic chassis designed for use with removable and different types of trailed or mounted implements and to drive stationary machinery. As a rule, motor cultivators are equipped with one or several power take-off shafts and active elements (for example, cutters), and a set of chain and pumping devices to them can consist of several dozen items [9].

For carrying out laboratory and field researches we made the special installation by means of which it is possible to work at the stationary laboratory and to carry out tests at the rate of the unit's work on one line or one row-spacing. The installation was made for a mini cultivator using a knapsack sprayer with a volume of 20 liters. This combination allows you to test the performance of the structure for a given treatment. The schematic flow diagram of the unit is shown in Figure 3. 


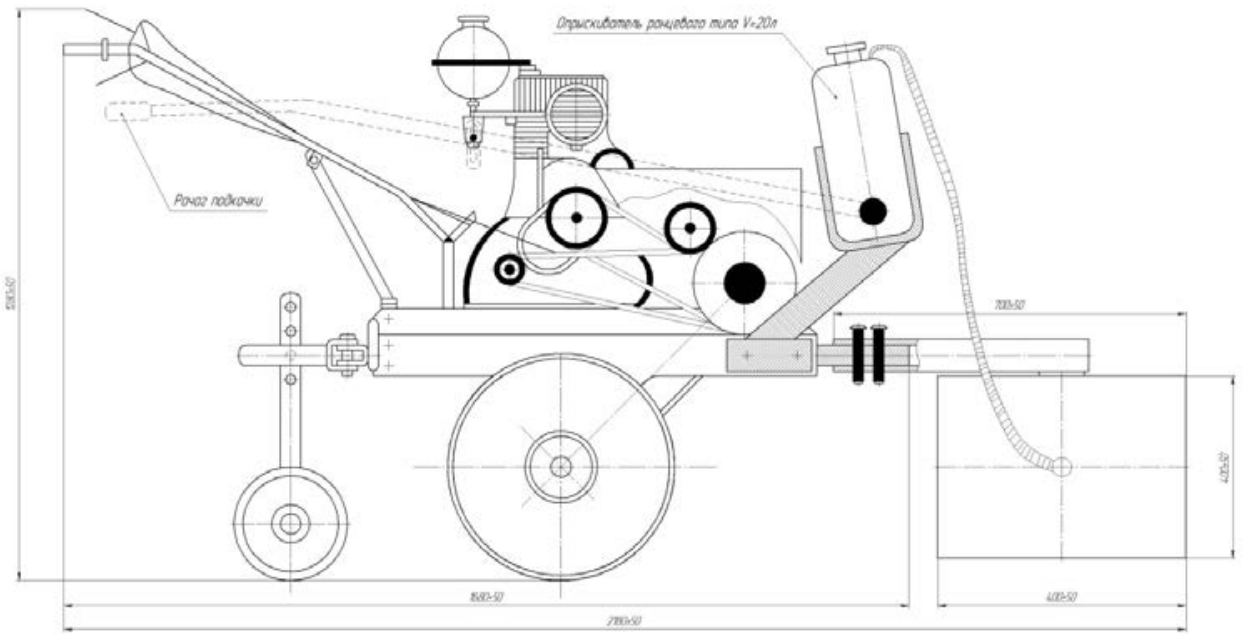

Fig. 3. Basic technological scheme of a unit.

According to the leading scientists, the total losses in crop production in Russia from pests, diseases and weeds in recent years are up to 100 million tons per year, in terms of grain-up to 40 million tons. The share of losses from weeds is quite high and practically comparable to that from pests and diseases combined.

To do this, we have proposed a comprehensive technology of care for row crops and perennial plantations with the use of modern means of plant protection (Figure 1 and 2). It is involved in the development of modern means of introduction of agrochemicals by point impact on weeds, foci of crop diseases and destruction of pests. All this will give us a limited use of agrochemicals which in turn will increase the environmental safety and quality of food in the country as a whole.

The unit works as follows. The liquid from the sprayer is fed through pipelines to the spraying devices located on the frame of the device and after that fed into a closed circuit.

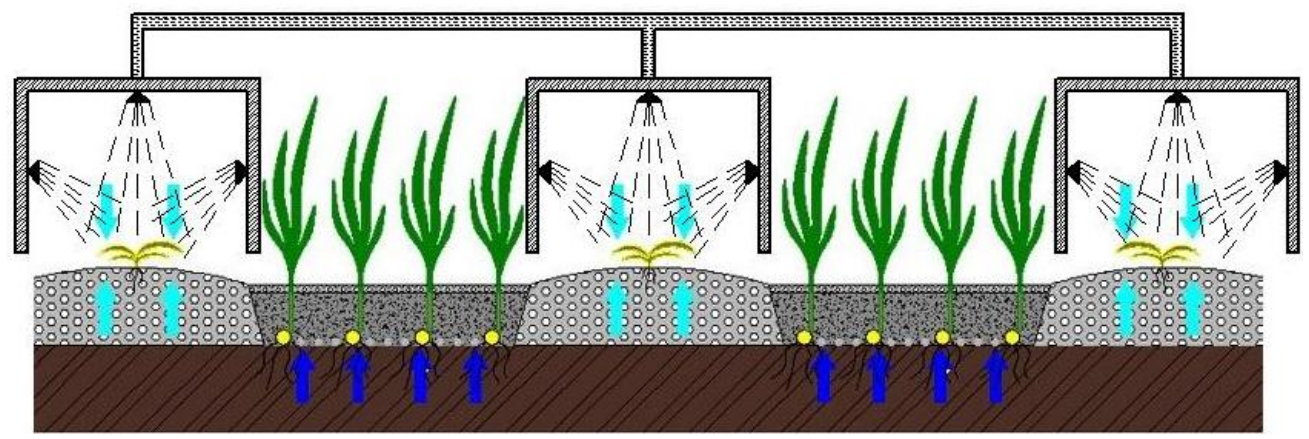

Fig. 4. Basic scheme of the unit's operation at row-spacing treatment. 


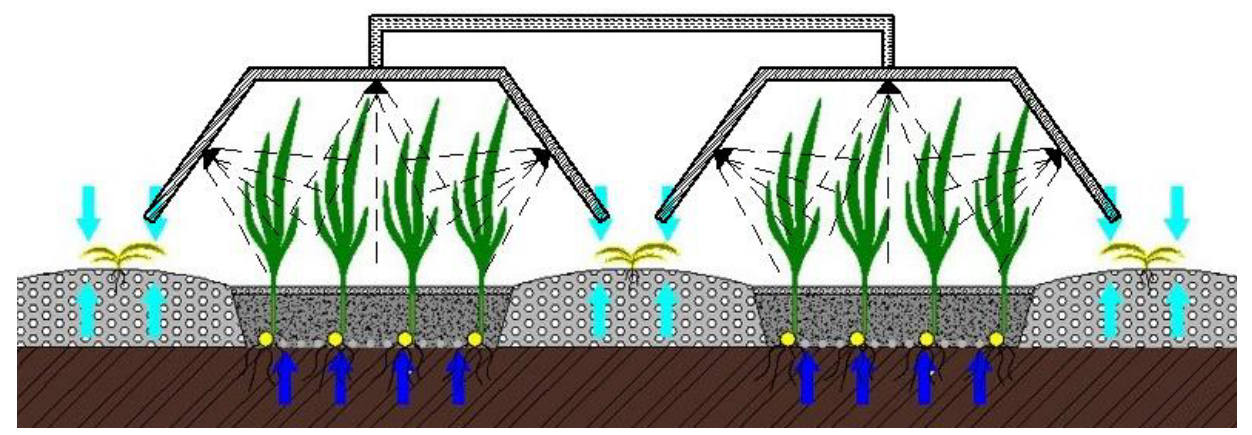

Fig. 5. Basic scheme of the unit's operation at additional fertilizing crops or treatment with phytoregulators .

The device for chemical plant protection contains a system of closed liquid application consisting of the base of side walls adjustable in width of grip depending on working conditions, one working element which is necessary for treatment of the maximum possible width of the grip as for the destruction of weeds in the row spacing of tilled crops and perennial plants without mechanical impact on the soil surface as for surface treatment of cultivated crops carrying out their additional fertilizing and pest control. The device contains sprayers located on the side walls to enter the liquid into a closed circuit, and the use of special sprayers will create a swirl that will give the liquid a smaller structure of drops and fall not only on the surface of the leaves from above, but also from the reverse side, this will significantly reduce the number of repeated treatments and rapid destruction of weed vegetation and the fast development of tilled crops with surface treatment. We designed the unit which is versatile, has the ability to adjust the width of grip, being directly on the frame without its dismantling, possibility of destroying weeds in a single pass of the unit, possibility of fertilizing of cultivated plants, regardless of weather conditions, except rain $[10]$.

As a result of the work done, we propose a new integrated energy-efficient technology of crop cultivation which is aimed at reducing the direct costs of crop production, increasing the environmental component of food. All this will lead to an increase in the number of products at a lower cost of its cultivation.

\section{References}

1. Kambulov, S.I. Improving the process of spraying field crops with liquid micronutrient fertilizers and pesticides (on the example of the complex fertilizer Aquadon-Micro) / Kambulov S.I., Vyalkov V.I., Khlystunov V.F., Volgin Y.N., Shevchenko N.V., Ovsyannikova G.V. // Grain economy of Russia. - 2009. - № 5. - p. 21-26.

2. Pakhomov, V.I. Technologies of applying organic, mineral, microelement fertilizers to increase the yield and quality of crop production under conditions of insufficient moisture / Pakhomov V.I., Rykov V.B., Kambulov S.I., Vyalkov V.I., Shevchenko N.V., Ksenz A.Y., Mazhara V.M. - Zernograd, State Scientific Institution SKNIIMESH Russian Agricultural Academy. - 2013. - 140 p.

3. E.I. Trubilin. The main soil cultivation with the formation turnover in modern working conditions and devices for its implementation / Trubilin E.I., Belousov S.V., Lepshina A.I. // The political network electronic scientific journal of the Kuban State Agrarian University. -2014. - No. 104.-C. 1902-1922. 
4. Belousov S.V. Communication of science and technology in the field of development of machines for the basic tillage of the soil with the circulation of the bed / Belousov S.V. // The political network electronic scientific journal of the Kuban State Agrarian University. -2015. No. 109.-C. 468-486.

5. Belousov S.V. Modern technologies of soil cultivation / Belousov S.V. // Scientific provision of the agro industrial complex. -2012. -FROM. 3-4.

6. Kambulov, S.I. Machine technologies of fertilization in the conditions of the southern steppe zone of Russia / Kambulov, SI, Rykov, VB, Lebedev, A.T., Ridny, SD, Pavlyuk, R.V., Lebedev, P.A. // Agrarian Scientific Center "Donskoy"; Stavropol State Agrarian University. - Stavropol. - 2017. - 160 p.

7. Pichugin, A.P. Moisture regime of leached chernozem under winter wheat, depending on its predecessor and method of increasing soil fertility / A.P. Pichugin // Grain farming. - 2008. - №1-2. - p.25-26.

8. Belousov S.V. Patent search for structures that provide soil treatment with the turnover of the reservoir. Search method. The proposed technical solution / Belousov S.V. // The political network electronic scientific journal of the Kuban State Agrarian University. 2015. No. 109.-C. 416-450.

9. Pakhomov, V.I. Results of a comparative assessment of mechanized technologies of cultivation of grain crops / V.I. Pakhomov, V.B. Rykov, S.I. Kambulov // Grain economy of Russia. - 2016. - № 1. - p. 58-62.

10. Kulintsev V.V. Scientific support for farming without tillage in the Stavropol Territory / V.V. Kulintsev, V.K. Drydiger // Ecologization of Agriculture and Optimization of Agrolandscapes // Coll. reports of the All-Russian Scientific and Practical Conference at the Research Institute of Agriculture and Soil Protection from Erosion on September 10-12, 2014. - Kursk: VNIIZIZPE. - 2014. - p. 33-38. 